\title{
Characterization of esophageal motility and esophagogastric junction in preterm infants with bronchopulmonary dysplasia
}

\author{
Maissa Rayyan ${ }^{1,2}$ (I) | Taher Omari ${ }^{3}$ (D) | Anne Debeer ${ }^{1,2}$ | Karel Allegaert ${ }^{2,4,5}$ (I) | \\ Nathalie Rommel ${ }^{6,7,8}$ (D)
}

${ }^{1}$ Neonatal Intensive Care Unit, University Hospitals Leuven, Leuven, Belgium

${ }^{2}$ Department of Development and Regeneration, KU Leuven, Leuven, Belgium

${ }^{3}$ College of Medicine \& Public health, Flinders University, Adelaide, Australia

${ }^{4}$ Department of Pharmaceutical and Pharmacological Sciences, KU Leuven, Leuven, Belgium

${ }^{5}$ Department of Clinical Pharmacy, Erasmus Medical Center, Rotterdam, The Netherlands

${ }^{6}$ Department of Neurosciences,

Experimental ORL, KU Leuven, Leuven, Belgium

${ }^{7}$ Neurogastroenterology and Motility, Gastroenterology, University Hospitals Leuven, Leuven, Belgium

${ }^{8}$ Translational Research Center for Gastrointestinal Disorders (TARGID), KU Leuven, Leuven, Belgium

\section{Correspondence}

Maissa Rayyan, Neonatal Intensive Care Unit, University Hospitals Leuven, Herestraat 49, B-3000 Leuven, Belgium. Email: maissa.rayyan@uzleuven.be

Funding information

Fund for clinical research, University Hospitals Leuven

\begin{abstract}
Background: To characterize esophageal motility and function of the esophagogastric junction (EGJ) in preterm infants with bronchopulmonary dysplasia (BPD).

Methods: High-resolution manometry with impedance was used to investigate esophageal motility and EGJ function in 28 tube-fed preterm infants with BPD. Patients with BPD were studied at term age during oral feeding. Thirteen healthy term-aged infants were included as controls. Esophageal analysis derived objective measures to evaluate esophageal contractile vigor, bolus distension pressure, EGJ relaxation, and EGJ barrier function (in rest and during respiration). In addition, we investigated the effect of BPD severity on these measures.

Key results: A total of 140 nutritive swallows were analyzed (BPD, $n=92$; controls, $n=48$ ). Normal esophageal peristaltic wave patterns were observed in all infants. BPD patients had higher distal contractile esophageal strength compared with controls (Kruskal-Wallis (KW) $P=.048$ ), and their deglutitive EGJ relaxation was comparable to controls. Severe BPD patients showed higher bolus distension pressures, higher EGJ resting pressures, and increased EGJ contractile integrals compared with mild BPD patients (Mann-Whitney U P $=.009, \mathrm{KW} P=.012$ and $\mathrm{KW} P=.028$, respectively).

Conclusions and Inferences: Preterm infants with BPD consistently present with normal peristaltic esophageal patterns following nutritive liquid swallows. The EGJ barrier tone and relaxation pressure appeared normal. In general, infants with BPD do not have altered esophageal motor function. There is however evidence for increased flow resistance at the EGJ in severe BPD patients possibly related to an increased contractility of the diaphragm.
\end{abstract}

\section{KEYWORDS}

bronchopulmonary dysplasia, dysphagia, impedance, lower esophageal sphincter, peristalsis of the esophagus, premature infant, high-resolution impedance manometry

Abbreviations: BPD, bronchopulmonary dysplasia; CD, crural diaphragm; CSI, contractile segment impedance; DCl, distal contractile integral; DL, distal latency; DPE, distension pressure during esophageal emptying; EGJ, esophagogastric junction; EGJ-CI, EGJ contractile integral; GER, gastroesophageal reflux; GERD, gastroesophageal reflux disease; HHHFNC, heated and humidified high-flow nasal cannula; HRIM, high-resolution impedance manometry; IR, impedance ratio; IRP4, 4-second integrated relaxation pressure; LES, lower esophageal sphincter; PMA, postmenstrual age; TLESR, transient lower esophageal sphincter relaxation; TZ, transition zone; UES, upper esophageal sphincter. 


\section{1 | INTRODUCTION}

Enteral feeding can be very challenging in preterm infants, particularly in preterm infants with associated comorbidities such as bronchopulmonary dysplasia (BPD). ${ }^{1}$ BPD is a lung disease, mostly presents in very preterm infants ( $<32$ weeks of gestation) and affecting almost half of extremely preterm infants $(<28$ weeks of gestation). ${ }^{2,3}$ Preterm infants with BPD are particularly prone to oral feeding problems and can be dependent on tube feeding after discharge. ${ }^{4-6}$ Yet, there are only limited research and evidence regarding the cause of those feeding problems.

Oral aversion, disturbed sucking-swallowing-breathing coordination, aspiration, respiratory insufficiency, gastroesophageal reflux disease (GERD) are thought to contribute to oral intake problems. ${ }^{5,7-9}$ Esophageal motility disorders can also cause feeding problems but have not been well explored in infants suffering from BPD. ${ }^{10}$ There is some evidence in healthy preterm infants that immaturity of pharyngeal motor function might play a role in nutritive deglutition. ${ }^{11}$ Additional description of esophageal motility patterns in infants with BPD during deglutition could improve the understanding of the role of esophageal motor dysfunction in feeding difficulties. For that purpose, enhanced pressure and impedance measurements can offer improved characterization of the mechanisms of esophageal bolus transport. ${ }^{12,13}$

With regards to gastroesophageal reflux (GER), data on the increased prevalence in infants with BPD are conflicting. ${ }^{14}$ The predominant mechanism of GER in preterm infants with and without BPD is transient relaxations of the lower esophageal sphincter (TLESRs)., ${ }^{9}$ Recently, an improved manometric diagnostic parameter, the EGJ contractile integral (EGJ-Cl), has been advocated as a measure to investigate non-deglutitive EGJ function in adults with GERD; however, its relevance in the neonatal and pediatric setting is unclear.

Because of the lack of data in young infants with BPD, we undertook a prospective study to describe esophageal bolus transport parameters during feeding and to explore both deglutitive and non-deglutitive functions of the EGJ in these infants.

\section{2 | MATERIALS AND METHODS}

The study was approved by the local ethical committee of University Hospitals Leuven (Belgian study number B322201214271). Written informed consent was obtained from all participants' primary caregivers before the start of the study. The included patients underwent high-resolution manometries related to the study protocol, in the absence of a specific clinical indication.

\section{1 | Patients}

\subsection{1 | Patients with BPD}

Preterm infants admitted in the neonatal intensive care unit (NICU) of the University Hospitals Leuven were eligible for the study when

\section{Key points}

- Preterm infants with BPD have normal peristaltic motor patterns following nutritive swallows.

- The EGJ barrier function seems unaffected in patients with BPD.

- There is evidence of increased flow resistance at the EGJ in patients with severe BPD possibly related to an increased contractility of the diaphragm.

diagnosed with BPD on the condition that they were still being fed by nasogastric tube at term age because of limited oral intake. BPD is defined based on the oxygen need at postnatal day 28 and is further specified as mild (oxygen FiO2 21\% at postmenstrual age (PMA) 36 weeks), moderate (oxygen $\mathrm{FiO} 2<30 \%$ at PMA 36 weeks), or severe BPD (positive pressure respiratory support and/or oxygen need $\mathrm{FiO} 2 \geq 30 \%$ at PMA 36 weeks). ${ }^{3}$ Heated and humidified high-flow nasal cannula (HHHFNC) and oxygen supplementation were not an exclusion criteria, but infants were only included if oral feeding was already introduced as part of their daily clinical care. Infants with oropharyngeal problems at risk for aspiration were not included in this study. Clinical data on age, weight (for PMA), ${ }^{16}$ oxygen need, respiratory support, drugs use (PPI, H2-blockers, prokinetic drugs, caffeine), and tube feeding or oxygen therapy at discharge were recorded.

\subsection{2 | Control patients}

Healthy term and former preterm infants at term age were included as controls. The healthy, preterm infants were studied as part of a parallel research study investigating maturational trends over time in preterm infants. ${ }^{17,18}$ The manometric studies at term age in preterm infants and the data collected in the healthy term infants were used as control data for the current study.

\section{2 | High-resolution impedance manometry recordings}

In infants with BPD and healthy preterm infants, the nasogastric tube was removed before start of the study. Type of respiratory support remained unchanged during the study. High-resolution manometry combined with impedance (HRIM) recordings were acquired using an $8 \mathrm{Fr}$ solid-state catheter (external diameter $2.7 \mathrm{~mm}$ ) incorporating 13 pressure sensors spaced $1 \mathrm{~cm}$, and 6 adjoining impedance segments, each $2 \mathrm{~cm}$ apart (Unisensor AG). Guided by a color screen plot in real time, the probe was passed along the esophagus with the tip through the lower esophageal sphincter (LES) and placed in the stomach ensuring that at least 1 pressure and 1 impedance channel was positioned in the stomach. A central lumen 


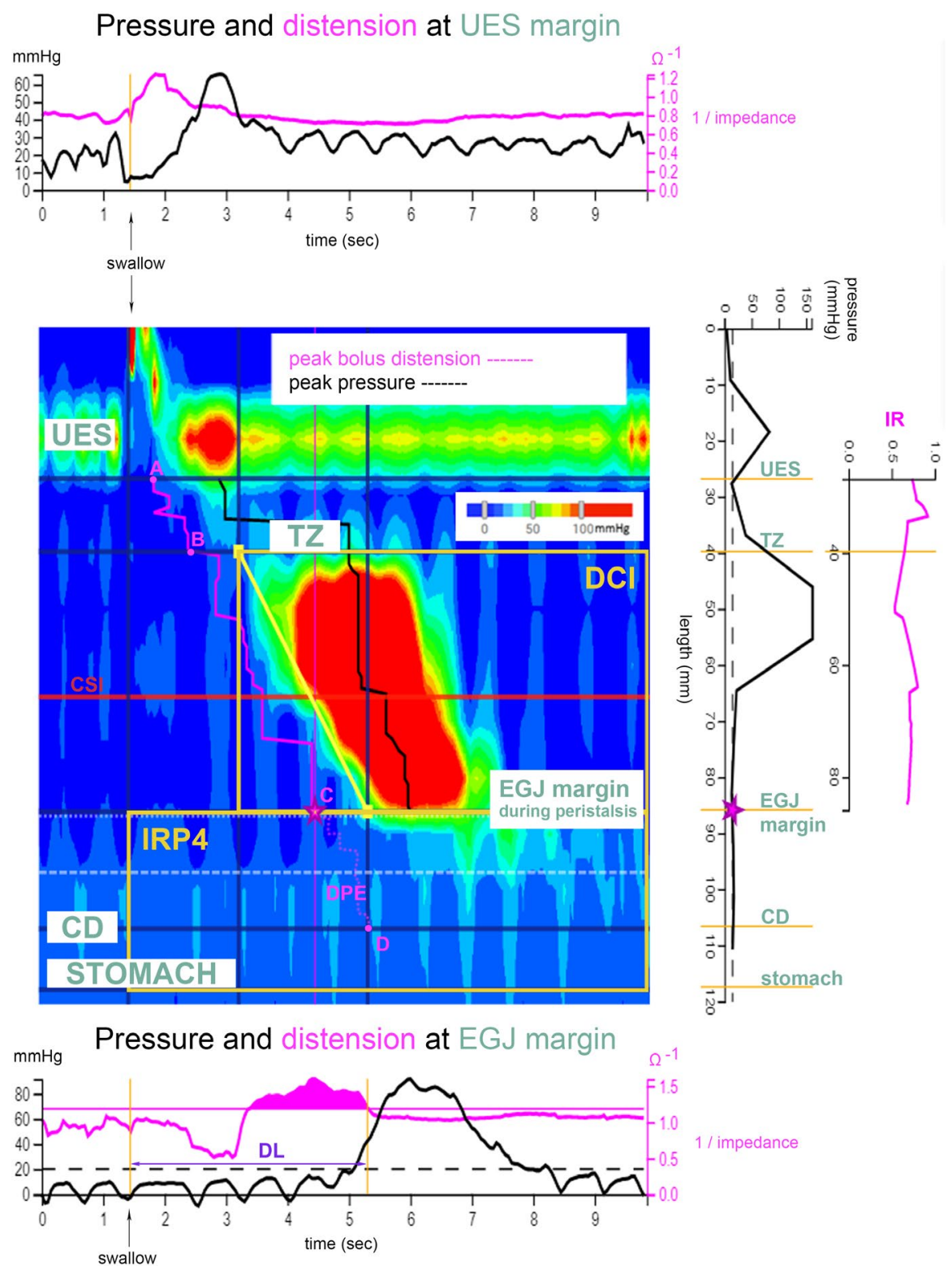

FIGURE 1 Derivation of esophageal pressure and impedance metrics. Esophageal pressure topography plot (Clouse plot) after swallowing of a bolus as described in Swallow Gateway ${ }^{\mathrm{T} M}$. Pressures amplitudes along the esophagus and at the level of the esophagogastric junction (EGJ) are reflected using a color code as a function of time. Distension of the esophagus as the bolus flow moves down the esophagus is determined using impedance. The pink impedance line indicates maximum esophageal distension along the esophagus. The plots on top and below the Clouse plot show the pressure and impedance signals at the upper esophageal sphincter (UES) and EGJ margins, respectively. Relaxation and contraction of the UES and EGJ are recorded (black line) as well as distension (pink line). The plot just right from the Clouse plot shows axial pressures recorded along the esophageal body at the exact time point of maximum distension of the esophageal lumen just proximal to the EGJ (pink asterisk). The following esophageal pressure topography metrics are displayed on the Clouse plot: distal latency time (DL), distal contractile integral (DCI), and EGJ-integrated relaxation pressure (IRP4). Pressure-impedance-derived metrics are shown in pink. Distension pressure during esophageal emptying (DPE from EGJ margin to crural diaphragm (CD), from C to D). Impedance ratio (IR) is depicted on the far right plot from the Clouse plot. IR is a parameter reflecting bolus clearance and is calculated by the average of all impedance ratio's values (nadir impedance/impedance at peak pressure) along the esophageal body from UES to EGJ. Contractile segment impedance (CSI) is measured at the distal one-third of the esophagus above the EGJ margin and determines the impedance at peak pressure (red line). A, lower margin UES; B, transition zone; C, EGJ margin; D, crural diaphragm. Abbreviations: CD, crural diaphragm; CSI, contractile segment impedance; DCl, distal contractile integral; DL, distal latency; DPE, distension pressure during esophageal emptying; EGJ, esophagogastric junction; IR, impedance ratio; IRP4, 4-s integrated relaxation pressure; TZ, transition zone; UES, upper esophageal sphincter

in the catheter was used for administration of feeding at the end of the study whenever infants needed to be supplemented after insufficient oral intake. The catheter was removed immediately after administration of the feed. Pressure and impedance data were acquired at 20 samples per second (Solar GI, Medical Measurement Systems). 


\begin{tabular}{|c|c|c|c|}
\hline & BPD & Healthy controls & $\begin{array}{l}\text { Healthy former } \\
\text { preterm controls }\end{array}$ \\
\hline $\begin{array}{l}\text { Number of patients } \\
\text { (n) }\end{array}$ & 28 (16 boys) & 3 (2 boys) & 10 (8 boys) \\
\hline GA (wks) & $26.2[24.3-28.3]$ & $37.0[36.3-38.4]$ & $30.4[28.4-31.4]$ \\
\hline Birth weight (g) & 755 [500-1060] & 3290 [3220-3320] & 1300 [670-1570] \\
\hline PNA at study (d) & 118 [54-171] & $62[31-62]$ & 47 [41-65] \\
\hline $\begin{array}{l}\text { PMA at study } \\
\text { (weeks) }\end{array}$ & $40.6[37.4-44.1]$ & $45.1[42.9-45.1]$ & $36.9[36.0-39.6]$ \\
\hline $\begin{array}{l}\text { Weight at study } \\
\text { (grams) }\end{array}$ & 2910 [2150-4102] & 4620 [3800-4900] & 2536 [2342-2890] \\
\hline Oxygen (n) & 10 & 0 & 0 \\
\hline HHHFNC (n) & 4 & 0 & 0 \\
\hline Home oxygen (n) & 7 & 0 & 0 \\
\hline $\begin{array}{l}\text { Home tube feeding } \\
\text { (n) }\end{array}$ & 8 & 0 & 0 \\
\hline
\end{tabular}

TABLE 1 Characteristics of patients with bronchopulmonary dysplasia and controls

Note: Median values [range] are displayed.

Abbreviations: BPD, bronchopulmonary dysplasia; GA, gestational age; HHHFNC, heated and humidified high-flow nasal cannula; PMA, postmenstrual age (GA + PNA); PNA, postnatal age.

All studies were performed bedside in the NICU. During all procedures, infants were monitored using oxygen saturation and ECG. Oral sucrose $24 \%$ was used for procedural analgesia before transnasal placement of the probe. A quiet environment was created, lights were dimmed, and parents were present to comfort their child. Infants were fed with a bottle in their habitual position with expressed breastmilk or formula milk. Normal saline was added to enhance the bolus conductivity for impedance measurements ( $1 / 10$ dilution of $\mathrm{NaCl} 0.9 \%)$. Infants were allowed to drink from a bottle ad libitum. Whenever oral bottle feeding proved to be difficult, boluses of $0.5 \mathrm{~mL}$ were given orally, using a syringe.

\section{3 | High-resolution impedance manometry analysis}

Normal peristaltic wave patterns were defined as the presence of propagating pressure waves post-deglutition along the esophagus from the upper esophageal sphincter (UES) to the EGJ. ${ }^{19}$ HRIM recordings were analyzed via the web application Swallow Gateway $^{\mathrm{TM}}$ (available at: swallowgateway.com) as recently described. ${ }^{20}$ The HRIM study was first exported from MMS as an ASCII file and then uploaded on the web application for further analysis. In this study, only nutritive swallows were selected and analyzed. The impedance signal at the distal UES margin was used to detect bolus flow consistent with nutritive swallows. Three EPT metrics were extracted, these included (Figure 1): (a) distal contractile integral (DCl), index of contractile vigor, calculated as the product of the amplitude, duration, and span of the distal esophageal contraction; (b) distal latency ( $D L$ ), the interval between UES and contractile deceleration point; and (c) IRP4 reflects the median EGJ pressure during 4 seconds of maximal relaxation after UES relaxation.

Three enhanced pressure-impedance-derived metrics were extracted (Figure 1): These were (a) intrabolus distension pressure during esophageal emptying (DPE); (b) impedance ratio (IR), impedance measure of bolus clearance and ineffective bolus transit; and (c) contractile segment impedance (CSI), the impedance value at peak esophageal contraction measured at the distal one-third above the EGJ margin. CSI can be used as a measure for mucosal integrity. ${ }^{21,22}$

For evaluation of EGJ barrier function, mean resting pressure and EGJ-Cl were determined at the onset of the manometric recording over three periods including three respiratory cycles above a threshold of gastric pressure. ${ }^{23}$ The EGJ contractile integral (EGJ-CI) defines the vigor of the EGJ barrier, independent of time. ${ }^{23}$ EGJ resting pressure is the pressure measured over the EGJ in rest, not related to swallowing, at the beginning of the study. The function of the UES and TLESRs were not evaluated as part of this study.

\section{4 | Statistical analysis}

Swallow parameters selected for each individual case were calculated as medians for comparison with controls. For BPD subgroup analysis, swallows were analyzed individually. Parameters were predominantly non-parametric; therefore, non-parametric statistical methods were conducted. Mann-Whitney $U$ (MWU) test and independent samples Kruskal-Wallis (KW) test (followed by post hoc Bonferroni correction when appropriate) were used. Statistical data analysis was conducted using IBM SPSS Statistics (IBM Corp, released 2017, version 26.0, IBM Corp, Armonk, NY). A P-value <.05 indicated statistical significance. 


\section{3 | RESULTS}

\section{1 | Cohort characteristics}

Twenty-eight former preterm infants with BPD at term equivalent age were included in this study (16 males, 12 females) and compared with 13 control patients (10 healthy preterm, 3 term). Patient characteristics are summarized in Table 1. The PMA of infants with BPD was 40.6 weeks (range 37.4-44.1 weeks). Z-scores for weight were $<-1$ at birth in 11/28 BPD patients. At the time of the manometric study, the number increased to 18 infants (PMA = 40 weeks; median weight loss, Z-score $=-1.13$ ). Two patients suffered from mild BPD, 9 patients from moderate BPD, and 17 from severe BPD. None of the included patients received CPAP or caffeine at the time of the study. Four patients were on nasal respiratory support with HHHFNC (2-4 L/minute). Patients were treated for GER according to the clinical judgment of the attending neonatologist. Fourteen BPD patients received anti-reflux treatment at the time of the manometric study and at discharge: domperidone $(n=10)$, erythromycin $(n=1)$, antacid agents ( $n=8)$, combination drug therapy $(n=6)$, and milk-thickening $(n=1)$. Eight of 28 BPD patients were discharged on tube feeding, none in the control group. A total of 140 nutritive swallows were analyzed as follows: 92 in BPD patients and 48 in controls. In 2 patients, esophageal analyses could not be performed due to long consecutive swallowing with deglutitive peristaltic inhibition or due to lack of an adequate bolus flow signal. EGJ evaluations were performed in all patients.

\subsection{Esophageal motility parameters}

Normal peristaltic wave patterns were observed in all BPD and control patients following nutritive swallows. Computed parameters during nutritive swallowing are summarized in Table 2. Higher DCl was observed in infants with BPD (KW P = .048). Among patients with $B P D, D C l$ was lower in the subgroup treated for GER (MWU $P=.043$ ). Patients with BPD treated for GER had similar esophageal mucosal integrity compared with those who were not (CSI, MWU $P=.72)$.

Table 3 summarizes details of patients grouped by type of BPD. Most patients included in the study had severe BPD (17/28). Birth weight of patients with severe BPD was lower compared to patients with mild BPD (KW $P=.046)$ despite a similar gestational age ( $K W$ $P=.688$ ). Days of parenteral nutrition were similar among BPD types (KW $P=.183)$. Patients with severe BPD seemed to be initiated to oral feeding later compared with mild, but this difference was statistically not significant (PMA 36 vs 34 weeks, KW P =.073). DPE was higher in patients with severe compared to mild BPD (MWU $P=.009$ ) (Figure 2). EGJ resting pressures and EGJ-Cl were significantly higher in patients with severe BPD compared to patients with mild BPD (KW $P=.012$ and $P=.028$, respectively), while only EGJ resting pressures and not EGJ-Cl were higher in patients with
TABLE 2 Esophageal pressure topography parameters and pressure-impedance parameters in infants with bronchopulmonary dysplasia and controls

\begin{tabular}{|c|c|c|}
\hline Parameter & BPD & Controls \\
\hline \multicolumn{3}{|c|}{ Esophageal pressure topography } \\
\hline $\mathrm{DCl}(\mathrm{mmHg} \cdot \mathrm{cm} . \mathrm{s})^{*}$ & 743 [201-1931] & $429[179-1112]$ \\
\hline $\mathrm{DL}(\mathrm{s})$ & $4.89[3.68-8.93]$ & $4.64[3.66-5.89]$ \\
\hline IRP4 (mmHg) & $9.4[0.5-51.0]$ & $13.9[3.4-30.0]$ \\
\hline $\begin{array}{l}\text { EGJ resting pressure } \\
(\mathrm{mmHg})\end{array}$ & $46.3[22.4-169.1]$ & $50.2[11.8-95.7]$ \\
\hline EGJ-Cl (mmHg.cm) & $46.6[20.6-186.0]$ & $45.4[8.5-88.0]$ \\
\hline \multicolumn{3}{|c|}{ Pressure-impedance parameters } \\
\hline $\mathrm{DPE}(\mathrm{mmHg})$ & $19[12-46]$ & 17 [12-33] \\
\hline IR & $0.67[0.56-0.84]$ & $0.70[0.56-0.84]$ \\
\hline $\operatorname{CSI}(\Omega)$ & $1013[596-1514]$ & 874 [703-1196] \\
\hline
\end{tabular}

Note: Median values [range] are given.

Abbreviations: BPD, bronchopulmonary dysplasia; CSI, contractile segment impedance; $\mathrm{DCl}$, distal contractile integral; DL, distal latency; $D P E$, distension pressure during esophageal emptying; EGJ resting pressure resting pressure at esophagogastric junction; EGJ-CI, EGJ contractile integral; IR, impedance ratio; IRP4, 4-second integrated relaxation pressure.

${ }^{*} P<.05$ Kruskal-Wallis test.

moderate compared to patients with mild BPD (KW P $=.020$ and $P=.065$, respectively). We also observed a direct association between IRP4 and DPE (Pearson $r=0.33, P=.0014$ ) (Figure 3). IRP4 was however not different in patients with BPD vs. non-BPD controls and not different among different subtypes of BPD.

\section{4 | DISCUSSION}

This study characterizes on the one hand esophageal bolus transport mechanisms and on the other hand the deglutitive and nondeglutitive EGJ function in infants with BPD. The main findings of this study were that esophageal motility in response to nutritive swallowing was similar in the overall group of infants with BPD compared to non-BPD controls, except for increased vigor of esophageal peristalsis observed in the BPD population. In cases where patients with BPD were treated for GER, this contractile vigor tended to be weaker. We also found that patients with severe BPD presented with increased $\mathrm{EGI}-\mathrm{Cl}$ and showed more resistance to bolus flow (higher DPE) in the distal esophagus. These findings are possibly related to increased contractility of the diaphragm in patients with severe BPD.

Gastroesophageal reflux is considered important in the management of BPD patients, and anti-reflux surgery has been advocated as GERD treatment in patients with severe BPD. ${ }^{24}$ However, the findings of this study do not reveal an impaired anti-reflux barrier function in patients with severe BPD. In fact, this study has demonstrated for the first time that BPD patients do not have lower EGJ resting pressures and $\mathrm{EGJ}-\mathrm{Cl}$ compared with non-BPD controls. 


\begin{tabular}{|c|c|c|c|}
\hline & Mild BPD & Moderate BPD & Severe BPD \\
\hline Number of patients & 2 & 9 & 17 \\
\hline $\begin{array}{l}\text { Number of analyzed } \\
\text { swallows }\end{array}$ & 4 & 36 & 52 \\
\hline \multicolumn{4}{|l|}{ Clinical characteristics } \\
\hline GA (wks) & 26.3 & $25.6[24.3-27.6]$ & $26.4[24.6-28.3]$ \\
\hline Birth weight $(g)^{a}$ & $920[870-970]$ & $770[500-1060]$ & $680[500-960]$ \\
\hline Days PN & $15.5[15-16]$ & $25[13-43]$ & 22 [14-129] \\
\hline PMA full enteral (wks) & $28.6[28.6-28.7]$ & $29.6[26.7-32.0]$ & $30.7[27.3-44.6]$ \\
\hline PMA first oral (wks) & $34.0[33.9-34.1]$ & $34.7[33.3-36.6]$ & $36.0[31.9-43.6]$ \\
\hline PMA full oral (wks) & 38 [37-39] & $40[37-44]$ & N/A \\
\hline Home tube feeding (n) & 0 & 0 & 8 \\
\hline $\begin{array}{l}\text { GER treatment } \\
\text { discharge }(n)\end{array}$ & 0 & 5 & 9 \\
\hline Home oxygen (n) & 0 & 0 & 7 \\
\hline \multicolumn{4}{|c|}{ Esophageal pressure topography } \\
\hline $\mathrm{DCl}(\mathrm{mmHg} . \mathrm{cm} . \mathrm{s})$ & $855 \pm 462$ & $815 \pm 808$ & $650 \pm 667$ \\
\hline $\mathrm{DL}(\mathrm{s})$ & $4.92 \pm 1.57$ & $5.26 \pm 1.47$ & $4.75 \pm 1.13$ \\
\hline IRP4 (mmHg) & $9.1 \pm 1.6$ & $9.2 \pm 18.1$ & $17.3 \pm 23.2$ \\
\hline $\begin{array}{l}\text { EGJ resting pressure } \\
(\mathrm{mmHg})^{\mathrm{b}}\end{array}$ & $29 \pm 16$ & $56 \pm 26$ & $49 \pm 26$ \\
\hline $\mathrm{EGJ}-\mathrm{Cl}(\mathrm{mmHg} \cdot \mathrm{cm})^{\mathrm{c}}$ & $30 \pm 23$ & $50 \pm 58$ & $48 \pm 26$ \\
\hline \multicolumn{4}{|c|}{ Pressure-impedance parameters } \\
\hline $\mathrm{DPE}(\mathrm{mmHg})^{\mathrm{d}}$ & $14 \pm 3$ & $21 \pm 11$ & $20 \pm 10$ \\
\hline IR & $0.74 \pm 0.07$ & $0.65 \pm 0.16$ & $0.68 \pm 0.15$ \\
\hline $\operatorname{CSI}(\Omega)$ & $926 \pm 297$ & $1123 \pm 459$ & $988 \pm 381$ \\
\hline
\end{tabular}

TABLE 3 Clinical characteristics and esophageal parameters in infants with mild, moderate, and severe bronchopulmonary dysplasia

Note: Parameters of clinical characteristics are displayed as median [range].

Parameters of individual swallows are displayed as median \pm IQR.

Abbreviations: BPD, bronchopulmonary dysplasia; CSI, contractile segment impedance; $\mathrm{DCI}$, distal contractile integral; DL, distal latency; DPE, distension pressure esophageal emptying; EGJ resting pressure, resting pressure at esophagogastric junction; EGJ-CI, EGJ contractile integral; GA, gestational age; GER, gastroesophageal reflux; IR, impedance ratio; IRP4, 4-second integrated relaxation pressure; PMA, postmenstrual age (gestational age + postnatal age); PN, parenteral nutrition.

${ }^{a}$ Kruskal-Wallis test $P<.05$ mild vs severe BPD.

${ }^{\mathrm{b}}$ Kruskal-Wallis test $P<.05$ mild vs moderate and vs severe BPD (post hoc Bonferroni corrected).

${ }^{c}$ Kruskal-Wallis test $P<.05$ mild vs severe BPD (post hoc Bonferroni corrected).

${ }^{\mathrm{d}}$ Mann-Whitney $U$ test $P<.01$ mild vs severe BPD.

Moreover, infants with severe BPD seem to have higher EGJ resting pressures and increased EGJ-Cl compared to infants with mild $\mathrm{BPD}$. The EGJ-Cl captures variations in EGJ barrier function during respiration, specifically assessing the pressure increase during inspiration. This metric is independent from the respiratory rate and is largely determined by contraction of the crural diaphragm and can therefore particularly be useful in infants with BPD. Our data show that the EGJ barrier during respiration was similar in all patients with BPD compared with healthy controls. This implies that in infants with BPD, the EGJ barrier function is preserved and should not be assumed to drive GER. TLESRs are however known to be the most common mechanism of GER in infants with BPD and could potentially be aggravated by increased gastroesophageal pressure gradients. ${ }^{9,25}$ While we did not gather objective measures of reflux, such as $\mathrm{pH}$-monitoring, in our study patients, esophageal mucosal integrity can be inferred using the $\mathrm{CSI}^{22,26} \mathrm{CSI}$ was not reduced in BPD and was comparable in patients with BPD irrespective of treatment for GER. This finding is consistent with evidence that many patients with BPD, who are treated for GERD, fail to demonstrate more GER on $\mathrm{pH}$-monitoring ${ }^{14,27,28}$ An alternative hypothesis could be that esophageal clearance due to increased bolus flow resistance at the EGJ is leading to retrograde flow, hereby increasing risk for aspiration and resembling esophageal regurgitation as seen in GER. Gastroesophageal regurgitation and retrograde esophageal bolus flow of residue secondary to outflow resistance may clinically present identical. The increased $\mathrm{DCl}$ seen in patients with BPD may 


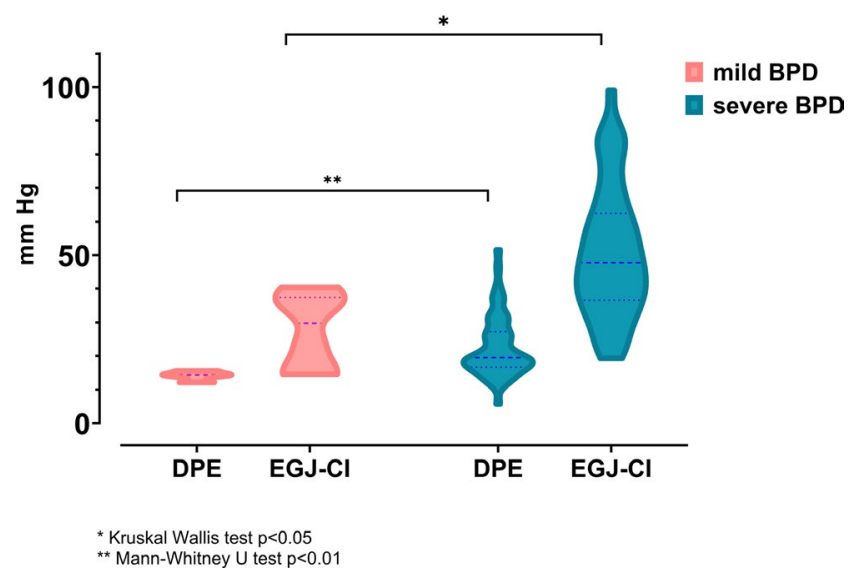

FIGURE 2 Distension pressure during esophageal emptying (DPE) and EGJ contractile integral (EGJ-CI) in mild vs severe infants with bronchopulmonary dysplasia (BPD)

represent the normal physiological augmentation of contractility as the esophageal body responds to outflow resistance. ${ }^{29}$ The intrabolus distension pressures during bolus esophageal emptying (DPE, pressure recorded just before the bolus passes the crural diaphragm) were increased in patients with severe BPD compared to infants with mild BPD. Augmentation of DPE suggests greater bolus flow resistance during emptying into the stomach. ${ }^{12}$ The observed augmentation of EGJ-Cl in infants with severe BPD could potentially indicate an increased outflow resistance caused by an increased contractility of the diaphragm observed in these infants. IRP4, the parameter typically used to reflect deglutitive EGJ relaxation, was not correspondingly increased in relation to bolus pressurization in the distal esophagus. However, IRP is a complex metric that is influenced by both bolus distension and contact pressures. ${ }^{30}$ IRP values can also be significantly elevated and highly variable in infants and therefore unable to detect more subtle variations within physiological ranges.

Nasal CPAP and HHHFNC are often used as respiratory support in infants with severe BPD. Feeding infants on continuous positive airway pressure remains controversial. ${ }^{31-33}$ The benefits of introducing feeding in a critical window must be weighed against the risk of laryngeal penetration, aspiration, and worsening of lung disease. A recent animal study not only provided evidence on safe bottle feeding and maintained sucking-swallowing-breathing coordination, but also on improved efficiency of bottle feeding in preterm and full-term lambs on nasal CPAP. ${ }^{34,35}$ The same group of researchers showed that nasal CPAP seems to inhibit GER in newborn lambs by increasing the barrier function of the EGJ. ${ }^{36}$ They believed that this was due to a decreased duration and depth of the transient relaxation of the LES. In the current study, the number of patients on respiratory support was limited. Only 4 of 28 patients were on HHHFNC (2-4 L/minute) and none were on nasal CPAP. Further studies on infants with BPD on nasal respiratory support are useful to elucidate the effect of this ventilation on the esophageal pressures and on the EGJ.

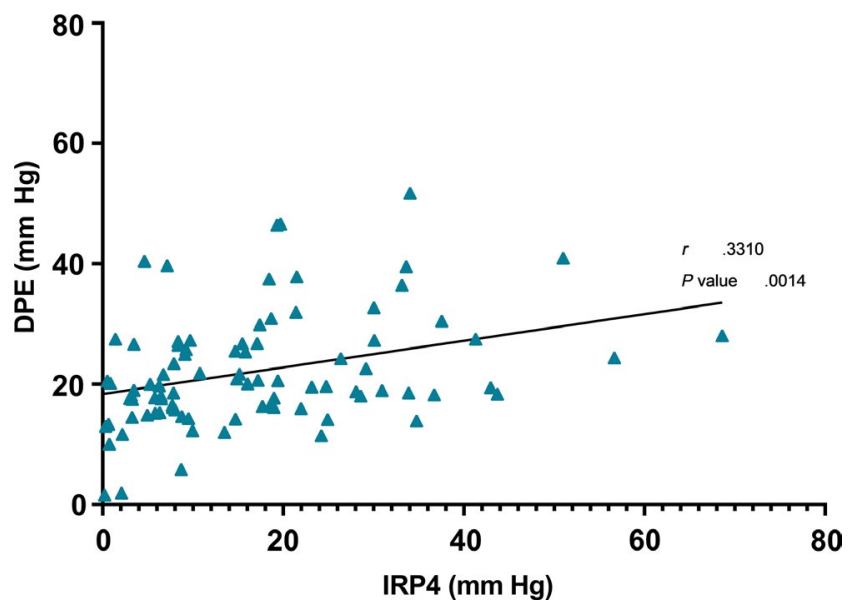

FIGURE 3 Linear regression of correlation between IRP4 and DPE of individual swallows in infants with BPD. A direct association is observed between IRP4 and DPE. DPE, distension pressure during esophageal emptying; IRP4, 4-s integrated relaxation pressure

The current study has some limitations that are important to acknowledge. First, most patients included in the study are infants with severe BPD. This is intrinsically related to the protocol since patients were only eligible for the study if they were still receiving tube feeding at term age. The number of mild patients with BPD that were compared with those with severe BPD is therefore limited. Conclusions should therefore be taken cautiously. Second, data are based on a small number of BPD and control subjects. Because of ethical considerations, the number of included healthy control subjects remains limited. Third, the volume of the oral bolus during swallows varied intra- and interpatient. Patients were allowed to drink ad libitum from a bottle and after oral bolus administration. However, the same volume of $0.5 \mathrm{ml}$ was administered orally, and the number of swallows in response to this bolus was variable. ${ }^{37}$ Fourth, we cannot exclude that prokinetic drugs like domperidone administered to infants with BPD influenced esophageal metrics such as an increase of LES resting pressure. Finally, control data originate from data from healthy term and preterm infants and are therefore different to preterm infants with BPD. These data are however acquired in the same circumstances and are currently the best data available.

In conclusion, we described esophageal motility and EGJ function in patients with BPD during feeding. Preterm infants with BPD have normal peristaltic motor patterns following nutritive swallows. Barrier function seemed unaffected in patients with BPD. In addition, we observed evidence of increased flow resistance at the EGJ in patients with severe BPD possibly related to an increased contractility of the diaphragm in these patients. More studies are needed to identify the role of nasal respiratory support on esophageal function in patients with severe BPD.

\section{ACKNOWLEDGEMENTS}

Maissa Rayyan was supported by the fund for clinical research, University Hospitals Leuven. 


\section{CONFLICT OF INTEREST}

Nathalie Rommel and Taher Omari hold a patent on AIMplot, the software used to analyze the pressure-impedance data. The open access Swallow Gateway ${ }^{\mathrm{TM}}$ resource is provided and hosted by Flinders University. None of the other authors has any potential conflict of interest to declare.

\section{AUTHOR CONTRIBUTIONS}

All the authors equally contributed to the manuscript.

\section{ORCID}

Maissa Rayyan iD https://orcid.org/0000-0001-5718-6887

Taher Omari iD https://orcid.org/0000-0001-5108-7378

Karel Allegaert iD https://orcid.org/0000-0001-9921-5105

Nathalie Rommel iD https://orcid.org/0000-0001-5675-7334

\section{REFERENCES}

1. Jadcherla SR, Wang M, Vijayapal AS, Leuthner SR. Impact of prematurity and co-morbidities on feeding milestones in neonates: a retrospective study. J Perinatol. 2010;30(3):201-208.

2. Stoll BJ, Hansen NI, Bell EF, et al. Trends in care practices, morbidity, and mortality of extremely preterm neonates, 1993-2012. JAMA. 2015;314(10):1039-1051.

3. Jobe AH, Bancalari E. Bronchopulmonary dysplasia. Am J Respir Crit Care Med. 2001;163(7):1723-1729.

4. Hwang YS, Ma MC, Tseng YM, Tsai WH. Associations among perinatal factors and age of achievement of full oral feeding in very preterm infants. Pediatrics and neonatology. 2013;54(5):309-314.

5. Pahsini K, Marinschek S, Khan Z, Urlesberger B, Scheer PJ, DunitzScheer M. Tube dependency as a result of prematurity. J NeonatalPerinatal Med. 2018;11(3):311-316.

6. Giannì ML, Sannino P, Bezze E, et al. Effect of co-morbidities on the development of oral feeding ability in pre-term infants: a retrospective study. Sci Rep. 2015;5:16603.

7. Gewolb IH, Vice FL. Abnormalities in the coordination of respiration and swallow in preterm infants with bronchopulmonary dysplasia. Dev Med Child Neurol. 2006;48(7):595-599.

8. Vice FL, Gewolb IH. Respiratory patterns and strategies during feeding in preterm infants. Dev Med Child Neurol. 2008;50(6):467-472.

9. Omari T, Barnett C, Snel A, et al. Mechanism of gastroesophageal reflux in premature infants with chronic lung disease. J Pediatr Surg. 1999;34(12):1795-1798.

10. Koppen IJN, Benninga MA, Singendonk M. Motility disorders in infants. Early Human Develop. 2017;114:1-6.

11. Rommel N, van Wijk M, Boets B, et al. Development of pharyngo-esophageal physiology during swallowing in the preterm infant. Neurogastroenterol Motil. 2011;23(10):e401-408.

12. Omari T, Connor F, McCall L, et al. A study of dysphagia symptoms and esophageal body function in children undergoing anti-reflux surgery. United Eur Gastroenterol J. 2018;6(6):819-829.

13. Singendonk MMJ, Omari TI, Rommel N, et al. Novel pressure-impedance parameters for evaluating esophageal function in pediatric achalasia. J Pediatr Gastroenterol Nutr. 2018;66(1):37-42.

14. Nobile S, Noviello C, Cobellis G, Carnielli VP. Are infants with bronchopulmonary dysplasia prone to gastroesophageal reflux? a prospective observational study with esophageal ph-impedance monitoring. J Pediatr. 2015;167(2):279-285.e1.

15. Omari TI, Barnett C, Snel A, et al. Mechanisms of gastroesophageal reflux in healthy premature infants. J Pediatr. 1998;133(5): 650-654.
16. Fenton TR, Kim JH. A systematic review and meta-analysis to revise the Fenton growth chart for preterm infants. BMC Pediatr. 2013;13:59.

17. Rayyan, M., Omari, T., Abu-Assi, R., et al. Effect of esophageal length on high-resolution manometry metrics: Extension to the neonatal population. Neurogastroenterology \& Motility. 2020;32.

18. Rayyan M, Omari T, Naulaers G, et al. Maturation of Esophageal Motility and Esophagogastric Junction in Preterm Infants. Neonatology. 2020.

19. Rommel N, Oman T, Staunton E, French J, Davidson G. Esophageal motility patterns in children with gastro-esophageal reflux disease. Gastroenterology. 2003;124(4):A258.

20. Singendonk MMJ, Ferris LF, McCall L, et al. High-resolution esophageal manometry in pediatrics: effect of esophageal length on diagnostic measures. Neurogastroenterol Motil. 2020;32(1):e13721.

21. Myers JC, Omari T. Esophageal impedance measured during peak peristaltic contraction correlates with endoscopic findings of mucosal inflammation in patients with gastro-esophageal reflux symptoms. Gastroenterology. 2014;146(5):S752-S752.

22. Mei L, Babaei A. Contractile Segment Impedance (Csi) during high-resolution impedance manometry highly correlates with intraluminal baseline impedance $(\mathrm{Bi})$, and is inversely related to esophageal acid exposure. Gastroenterology. 2018;154(6):S85-S86.

23. Gyawali CP, Roman S, Bredenoord AJ, et al. Classification of esophageal motor findings in gastro-esophageal reflux disease: Conclusions from an international consensus group. Neurogastroenterol Motil. 2017;29(12):e13104.

24. Jensen EA, Munson DA, Zhang H, Blinman TA, Kirpalani H. Antigastroesophageal reflux surgery in infants with severe bronchopulmonary dysplasia. Pediatr Pulmonol. 2015;50(6):584-587.

25. Pauwels A, Blondeau K, Dupont LJ, Sifrim D. Mechanisms of increased gastroesophageal reflux in patients with cystic fibrosis. Am J Gastroenterol. 2012;107(9):1346-1353.

26. Omari T, Mc Call L, Seiboth $\mathrm{G}$, et al. Contractile segment impedance (CSI) for the diagnosis of gastroesophageal reflux disease during high resolution esophageal manometry: a pediatric study. J Pediatr Gastroenterol Nutr. 2019;68(Supplement 1):6-7.

27. Akinola E, Rosenkrantz TS, Pappagallo M, McKay K, Hussain N. Gastroesophageal reflux in infants $<32$ weeks gestational age at birth: lack of relationship to chronic lung disease. Am J Perinatol. 2004;21(2):57-62.

28. Fuloria M, Hiatt D, Dillard RG, O'Shea TM. Gastroesophageal reflux in very low birth weight infants: association with chronic lung disease and outcomes through 1 year of age. J Perinatol. 2000;20(4):235-239.

29. Brink GJ, Lei WY, Omari TI, et al. Physiological augmentation of esophageal distension pressure and peristalsis during conditions of increased esophageal emptying resistance. Neurogastroenterol Motil. 2018;30(4):e13225.

30. Omari TI, Wauters L, Rommel N, Kritas S, Myers JC. Oesophageal pressure-flow metrics in relation to bolus volume, bolus consistency, and bolus perception. United European Gastroenterol J. 2013;1(4):249-258.

31. Dodrill P, Gosa M, Thoyre S, et al. FIRST, DO NO HARM: a response to "oral alimentation in neonatal and adult populations requiring high-flow oxygen via nasal cannula". Dysphagia. 2016;31(6):781-782.

32. Jadcherla SR, Bhandari V. "Pressure" to feed the preterm newborn: associated with "positive" outcomes? Pediatr Res. 2017;82(6):899-900.

33. Leder SB, Siner JM, Bizzarro MJ, McGinley BM, Lefton-Greif MA. Oral alimentation in neonatal and adult populations requiring highflow oxygen via nasal cannula. Dysphagia. 2016;31(2):154-159.

34. Samson N, Michaud A, Othman R, et al. Nasal continuous positive airway pressure influences bottle-feeding in preterm lambs. Pediatr Res. 2017;82(6):926-933. 
35. Samson N, Nadeau C, Vincent L, Cantin D, Praud JP. Effects of nasal continuous positive airway pressure and high-flow nasal cannula on sucking, swallowing, and breathing during bottle-feeding in lambs. Front Pediatr. 2017;5:296.

36. Djeddi D, Cantin D, Samson N, Praud JP. Nasal continuous positive airway pressure inhibits gastroesophageal reflux in newborn lambs. PLoS ONE. 2014;9(9):e107736.

37. Hasenstab KA, Sitaram S, Lang IM, Shaker R, Jadcherla SR. Maturation modulates pharyngeal-stimulus provoked pharyngeal and respiratory rhythms in human infants. Dysphagia. 2018;33(1):63-75.
How to cite this article: Rayyan M, Omari T, Debeer A, Allegaert K, Rommel N. Characterization of esophageal motility and esophagogastric junction in preterm infants with bronchopulmonary dysplasia. Neurogastroenterol Motil. 2020;00:e13849. https://doi.org/10.1111/nmo.13849 